Pacific Journal of Mathematics

FIXED POINT AND COINCIDENCE SETS OF BICONNECTED 


\title{
FIXED POINT AND COINCIDENCE SETS OF BICONNECTED MULTIFUNCTIONS ON TREES
}

\author{
HELGA SCHIRMER
}

\begin{abstract}
Various properties of fixed point sets of monotone singlevalued mappings on dendrites have been studied by $L$. E. Ward, Jr. and the author. Some of them are extended here to coincidences of two mappings between two trees, and to biconnected multifunctions. Examples are given which show that others are no longer true in these cases.
\end{abstract}

1. Introduction. We know several properties of fixed point sets of monotone mappings onto dendrites. A theorem by G. E. Schweigert [5] and L. E. Ward, Jr. [6] states that every monotone mapping of a dendrite onto itself which leaves one end point fixed also leaves at least one other point fixed. Further results are contained in [3], where e.g., monotone mappings which leave all end points or all but finitely many end points fixed are investigated. It is shown in [3] that the fixed point set contains all branch points of order $\geqq n$ if it contains all but $n$ of the end points.

The theorem by Schweigert and Ward has been extended in [4] in two directions: from fixed points to coincidences of two mappings, and from monotone single-valued mappings to biconnected multifunctions. The purpose of the present paper is an attempt to extend results from [3] in a similar way. But this is not entirely possible. In the Main Theorem (see §3) we only prove that points of order $\geqq n+3$ rather than order $\geqq n$ are invariant, and examples in $\S 4$ show that this statement cannot be sharpened to include points of order $\leqq n+2$. Neither can another result from [3], namely the non-existence of a fixed point set consisting of two points of order two for monotone surjections of dendrites, be extended to coincidences or to biconnected multifunctions, as can be seen from two examples given at the end.

A dendrite is a metric tree. The conclusions of this paper are valid for trees, as a metric is not needed in the proofs.

2. Trees and multifunctions. A tree is a continuum (i.e., compact connected Hausdorff space) in which every pair of points is separated by a third one. We use the partial order structure of trees which was developed by L. E. Ward, Jr. [6, 7]. It is obtained by selecting an arbitrary point $r \in T$ as root, and defining $x \leqq y$ if $x=r, x=y$, or $x$ separates $r$ and $y$. Let 


$$
\begin{aligned}
& L(x)=\{y \in T \mid y \leqq x\} \\
& M(x)=\{y \in T \mid x \leqq y\}
\end{aligned}
$$

Then $L(x)$ and $M(x)$ are closed for every $x \in T$, and $M(x) \backslash\{x\}$ is open. If $x<y$, then the (linearly ordered) set $[x, y]=M(x) \cap L(y)$ is connected [6]. A connected subset $A$ of $T$ which contains the points $x$ and $y$, where $x<y$, also contains $[x, y]$, for $M(z) \backslash\{z\}$ and $T \backslash M(z)$ would induce a separation of $A$ if $z \in[x, y]$ but $z \notin A$.

A point $m \in A$ is called a maximum of the subset $A$ of $T$ if $m \nless x$ for every $x \in A$. A root $r \in A$ is a point such that $r \leqq x$ for every $x \in A$. Every nonempty closed subset of $T$ has a maximum [6, Theorem 1], and every nonempty closed connected subset has a root [1, Lemma 2]. We define the order of a point $a \in T$ as the number of components of $T \backslash\{a\}$. An end point is a point of order one, a branch point is a point of order $\geqq 3$.

The following lemma will be needed in the proof of the Main Theorem.

Lemma. If $a \in T$, then every component of $T \backslash\{a\}$ contains either the root or an end point.

Proof. This lemma was proved in [3, Lemma 5.2] for dendrites. It is easy to adapt the proof given there to the nonmetric case.

A multifunction $\varphi: X \rightarrow X^{\prime}$ from a space $X$ into a space $X^{\prime}$ is a correspondence which assigns to each point of $X$ a nonempty subset of $X^{\prime}$. We say that $\varphi$ is point-closed if $\varphi(x)$ is closed for every $x \in X$. It is called connected if $\varphi(A)=U(\varphi(x) \mid x \in A)$ is a connected subset of $X^{\prime}$ whenever $A$ is a connected subset of $X$, inverse-connected if $\varphi^{-1}\left(A^{\prime}\right)=$ $\left\{x \in X \mid \varphi(x) \cap A^{\prime} \neq \phi\right\}$ is a connected subset of $X$ whenever $A^{\prime}$ is a connected subset of $X^{\prime}$, and biconnected if it is both connected and inverseconnected. If $\varphi: T \rightarrow T^{\prime}$ is a point-closed and biconnected multifunction from a tree $T$ into a tree $T^{\prime}$, then $\varphi(x)$ is a nonempty, closed and connected subset of $T^{\prime}$ for every $x \in T$ and hence has a root, which we denote by $f(x)$. The function $f: T \rightarrow T^{\prime}$ is single-valued, but in general not continuous. If $f$ transforms the root of $T$ onto the root of $T^{\prime}$, then $f$ is isotone (i.e., $x \leqq y$ in $T$ implies $f(x) \leqq f(y)$ in $T^{\prime}$ ), as the proof of Lemma 2 in [4] stillh olds for point-closed instead of upper semicontinuous (usc) multi-functions.

3. Results. We shall now state and prove the theorem which is the main result of this paper. It concerns coincidences of multifunctions, and specializes to fixed points. 
Definition. A fixed point of a multifunction $\varphi: X \rightarrow X$ is a point $x \in X$ with $x \in \varphi(x)$. A coincidence of two multifunctions $\varphi, \psi: X \rightarrow X^{\prime}$ is a point $x \in X$ with $\varphi(x) \cap \psi(x) \neq \phi$.

MaIN Theorem. Let $\varphi, \psi: T \rightarrow T^{\prime}$ be two point-closed and biconnected multifunctions from a tree $T$ onto a tree $T^{\prime}$. If all but $n$ of the end points are coincidences, then all points of order $\geqq n+3$ are coincidences.

Proof. If $b \in T$ is a branch point of order $\geqq n+3$, then $T \backslash\{b\}$ consists of at least $n+3$ components. Therefore we see from the Lemma in $\S 2$ that $T$ has at least $n+2$ end points. By assumption all but $n$ of these are coincidences, hence we can select a point $e_{0}$ as root for $T$ which is both an end point and a coincidence. Select also a point $e_{0}^{\prime} \in \varphi\left(e_{0}\right) \cap \psi\left(e_{0}\right)$ as root of $T^{\prime \prime}$.

The Lemma permits us now to choose in each component of $T \backslash\{b\}$ which does not contain $e_{0}$ an end point. Thus we obtain at least $n+2$ end points, and according to the assumptions of the Main Theorem at least two of them must be coincidences. Call them $e_{1}$ and $e_{2}$.

Then $b<e_{1}$, as otherwise the maximum $m=\max \left[L(b) \cap L\left(e_{1}\right)\right]<b$, so that the connected set $\left[e_{0}, m\right] \cup\left[m, e_{1}\right]$ would contain both $e_{0}$ and $e_{1}$ but not $b$. As $e_{0}$ and $e_{1}$ have been chosen in different components of $T \backslash\{b\}$, this is impossible. Similarly we have $b<e_{2}$.

Now select points $e_{i}^{\prime} \in \varphi\left(e_{i}\right) \cap \psi\left(e_{i}\right)$ for $i=1,2$, and let the maximum of $L\left(e_{1}^{\prime}\right) \cap L\left(e_{2}^{\prime}\right)$ be $b^{\prime}$. As $f$ is an isotone function, we have

$$
f\left(e_{0}\right)=e_{0}^{\prime} \leqq f(b) \leqq f\left(e_{i}\right) \leqq e_{i}^{\prime} \quad(i=1,2),
$$

hence $f(b) \leqq b^{\prime} \leqq e_{i}^{\prime}$. Therefore the connected set $\varphi\left(\left[b, e_{i}\right]\right)$, which contains both $f(b)$ and $e_{i}^{\prime}$, must also contain $\left[f(b), e_{i}^{\prime}\right]$ and hence $b^{\prime}$. From this we see that there exist points $x_{i} \in\left[b, e_{i}\right]$ for $i=1,2$ with $b^{\prime} \in \varphi\left(x_{i}\right)$.

We now repeat the argument with the points $e_{0}$ and $e_{1}$ interchanged (i.e., with $e_{1}$ as root of $T$ ), and see that there also exists a point $x_{0}$ which separates $e_{0}$ and $b$, and for which $b^{\prime} \in \varphi\left(x_{0}\right)$.

Now take again $e_{0}$ as root. As $x_{j} \in \varphi^{-1}\left(b^{\prime}\right)$ for $j=0,1$, it follows that $\left[x_{0}, x_{1}\right] \in \varphi^{-1}\left(b^{\prime}\right)$. But $b \in\left[x_{0}, x_{1}\right]$, hence $b \in \varphi^{-1}\left(b^{\prime}\right)$ or $b^{\prime} \in \varphi(b)$. In the same way it follows that $b^{\prime} \in \psi(b)$, so that $b$ is a coincidence of $\varphi$ and $\psi$.

The following corollary is obtained from the Main Theorem by taking $n=0$.

CoROLlary 1. If all end points are coincidences of two pointclosed and biconnected multifunctions from one tree onto another, then 
all branch points are coincidences.

A further special case of interest is the fixed point case, i.e., the case where $T=T^{\prime}$ and $\psi$ is the identity mapping $\psi(x)=x$.

CoROLlary 2. Let $\varphi: T \rightarrow T$ be a point-closed and biconnected multifunction of a tree $T$ onto itself. If the fixed point set of $\varphi$ contains all but $n$ of the end points, then it contains all branch points of order $\geqq n+3$.

4. Remarks. The following theorem was proved in [3, Theorem 5.1]: If $f: D \rightarrow D$ is a monotone mapping of a dendrite $D$ (i.e., a metric tree) onto itself, and if at most $n$ end points of $D$ are not fixed, then every point of order $n$ (where $n \geqq 3$ ) is fixed. In view of this result it might be expected that the Main Theorem can be sharpened to include branch points of order $n$ instead of $n+3$. But this is not the case, not even for fixed points of point-closed and biconnected multifunctions or for coincidences of monotone single-valued mappings, as the next two examples show.

ExAmple 1. Let $T$ be the tree (triod) in the $x y$-plane with end points $e_{1}=(0,-1), e_{2}=(0,1)$, and $e_{3}=(1,0)$, and branch point $b=$ $(0,0)$ of order three. Let further $a=(0,-(1 / 2))$ and $c=(0,1 / 2)$. Define a single-valued and linear mapping $f: T \rightarrow T$ by $f\left(e_{1}\right)=e_{1}$, $f\left(e_{2}\right)=e_{2}, f\left(e_{3}\right)=a, f(b)=a, f(c)=b$; and let $\varphi: T \rightarrow T$ be defined by $\varphi(x)=f(x)$ if $x \in T \backslash\{c\}, \varphi(c)=\left[b, e_{3}\right]$. Then $\varphi$ is point-closed and biconnected, leaves only the end point $e_{3}$ not fixed, but leaves also the branch point $b$ of order 3 not fixed. Hence Corollary 2 does not hold if $n+3$ is replaced by $n+2$.

ExAmple 2. Let $T$ be the triod of Example 1 with vertices $\left\{e_{1}, e_{2}, e_{3}, b\right\}$, and let $T^{\prime \prime}$ be the segment $\left[e_{1}, e_{2}\right]$. Take $f: T \rightarrow T^{\prime}$ as the linear mapping determined by $f\left(e_{1}\right)=f\left(e_{3}\right)=f(b)=e_{1}, f\left(e_{2}\right)=e_{2}$, and $g: T \rightarrow T^{\prime}$ as the linear mapping determined by $g\left(e_{1}\right)=e_{1}, g\left(e_{2}\right)=g\left(e_{3}\right)=$ $g(b)=e_{2}$. Then the end points $e_{1}$ and $e_{2}$ are coincidences, but $e_{3}$ and $b$ are not coincidences. Hence the Main Theorem cannot even in the single-valued case be strengthened to include points of order $n+2$.

The theorem by Schweigert and Ward mentioned in the introduction states that the fixed point set of a monotone mapping of a tree onto itself cannot consist of one point of order one. This result was extended in [3, Theorem 4.1(i)], where it was proved that the fixed point set also cannot consist of two points of order two. We conclude by giving two examples which show that this extension is not valid for fixed points of point-closed and biconnected multifunctions, or for 
coincidences of monotone mappings.

EXAMPLE 3. Let $T$ be the segment $\left[e_{1}, e_{2}\right]$ and define $a$ and $c$ as in Example 1. Define a multifunction $\varphi: T \rightarrow T$ by $\varphi(x)=a$ for $x \epsilon$ $\left[e_{1}, \alpha\right), \varphi(\alpha)=\left[e_{1}, a\right], \varphi(x)=1 / 4+x-x^{2}$ for $x \in(a, c), \varphi(c)=\left[c, e_{2}\right], \varphi(x)=c$ for $x \in\left(b, e_{2}\right]$. Then $\varphi$ is point-closed and biconnected, and its fixed point set consists of the two points $a$ and $c$ which are both of order two.

EXAMPLE 4. Let again $T$ have the vertices $\left\{e_{1}, e_{2}, e_{3}, a, b, c\right\}$, and let $T^{\prime}$ be the subtree with vertices $\left\{e_{1}, e_{2}, a, c\right\}$. Let $f, g: T \rightarrow T^{\prime}$ be the linear mappings determined by $f\left(e_{1}\right)=e_{1}, f\left(e_{2}\right)=f(b)=f(c)=c$, $f\left(e_{3}\right)=e_{2}, f(a)=a$, and $g\left(e_{1}\right)=g(a)=g(b)=a, g\left(e_{2}\right)=e_{2}, g\left(e_{3}\right)=e_{1}, g(c)=c$. Then the coincidence set of $f$ and $g$ consists of the two points $\alpha$ and $c$ of order two.

\section{REFERENCES}

1. C. E. Capel and W. L. Strother, Multi-valued functions and partial order, Portugal. Math., 17 (1958), 41-47.

2. C. Eberhart, Metrizability of trees, Fund. Math., 65 (1969), 43-50.

3. H. Schirmer, Properties of fixed point sets on dendrites, Pacific J. Math., 36 (1971), $795-810$.

4. - Biconnected multifunctions of trees which have an end point as fixed point or coincidence, Canad. J. Math., 23 (1971), 461-467.

5. G. E. Schweigert, Fixed elements and periodic types for homeomorphisms on s.l.c. continua, Amer. J. Math., 66 (1944), 229-244.

6. L. E. Ward, Jr., Partially ordered topological spaces, Proc. Amer. Math. Soc., 5 (1954), 144-161.

7. - A note on dendrites and trees, Proc. Amer. Math. Soc., 5 (1954), 992-994.

Received February 18, 1971 and in revised form April 19, 1971. This research was partially supported by the National Research Council of Canada (Grant A7579).

Carleton University, Ottawa, Canada. 



\title{
PACIFIC JOURNAL OF MATHEMATICS
}

\section{EDITORS}

\author{
H. SAMELSON \\ Stanford University \\ Stanford, California 94305 \\ C. R. HobBY \\ University of Washington \\ Seattle, Washington 98105
}

J. DugundJI

Department of Mathematics

University of Southern California

Los Angeles, California 90007

RICHARD ARENS

University of California

Los Angeles, California 90024

\section{ASSOCIATE EDITORS}
E. F. BECKENBACH
B. H. NeumanN
F. WOLF
K. YOSHIDA

\section{SUPPORTING INSTITUTIONS}

\author{
UNIVERSITY OF BRITISH COLUMBIA \\ CALIFORNIA INSTITUTE OF TECHNOLOGY \\ UNIVERSITY OF CALIFORNIA \\ MONTANA STATE UNIVERSITY \\ UNIVERSITY OF NEVADA \\ NEW MEXICO STATE UNIVERSITY \\ OREGON STATE UNIVERSITY \\ UNIVERSITY OF OREGON \\ OSAKA UNIVERSITY
}

\author{
UNIVERSITY OF SOUTHERN CALIFORNIA \\ STANFORD UNIVERSITY \\ UNIVERSITY OF TOKYO \\ UNIVERSITY OF UTAH \\ WASHINGTON STATE UNIVERSITY \\ UNIVERSITY OF WASHINGTON
AMERICAN MATHEMATICAL SOCIETY
NAVAL WEAPONS CENTER

The Supporting Institutions listed above contribute to the cost of publication of this Journal, but they are not owners or publishers and have no responsibility for its content or policies.

Mathematical papers intended for publication in the Pacific Journal of Mathematics should be in typed form or offset-reproduced, (not dittoed), double spaced with large margins. Underline Greek letters in red, German in green, and script in blue. The first paragraph or two must be capable of being used separately as a synopsis of the entire paper. The editorial "we" must not be used in the synopsis, and items of the bibliography should not be cited there unless absolutely necessary, in which case they must be identified by author and Journal, rather than by item number. Manuscripts, in duplicate if possible, may be sent to any one of the four editors. Please classify according to the scheme of Math. Rev. Index to Vol. 39. All other communications to the editors should be addressed to the managing editor, Richard Arens, University of California, Los Angeles, California, 90024.

50 reprints are provided free for each article; additional copies may be obtained at cost in multiples of 50 .

The Pacific Journal of Mathematics is published monthly. Effective with Volume 16 the price per volume (3 numbers) is $\$ 8.00$; single issues, $\$ 3.00$. Special price for current issues to individual faculty members of supporting institutions and to individual members of the American Mathematical Society: $\$ 4.00$ per volume; single issues $\$ 1.50$. Back numbers are available.

Subscriptions, orders for back numbers, and changes of address should be sent to Pacific Journal of Mathematics, 103 Highland Boulevard, Berkeley, California, 94708.

\section{PUBLISHED BY PACIFIC JOURNAL OF MATHEMATICS, A NON-PROFIT CORPORATION}

Printed at Kokusai Bunken Insatsusha (International Academic Printing Co., Ltd.), 270, 3chome Totsuka-cho, Shinjuku-ku, Tokyo 160, Japan. 


\section{Pacific Journal of Mathematics}

\section{Vol. 40, No. $2 \quad$ October, 1972}

Louis I. Alpert and L. V. Toralballa, An elementary definition of surface area in $E^{n+1}$ for smooth surfaces...........................

Eamon Boyd Barrett, A three point condition for surfaces of constant mean curvature........................................

Jan-Erik Björk, On the spectral radius formula in Banach algebras ....... 279

Peter Botta, Matrix inequalities and kernels of linear transformations . . . . 285

Bennett Eisenberg, Baxter's theorem and Varberg's conjecture ........... 291

Heinrich W. Guggenheimer, Approximation of curves .............. 301

A. Hedayat, An algebraic property of the totally symmetric loops associated with Kirkman-Steiner triple systems ....................... 305

Richard Howard Herman and Michael Charles Reed, Covariant representations of infinite tensor product algebras ................

Domingo Antonio Herrero, Analytic continuation of inner

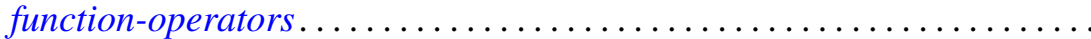

Franklin Lowenthal, Uniform finite generation of the affine group......... 341

Stephen H. McCleary, 0-primitive ordered permutation groups .......... 349

Malcolm Jay Sherman, Disjoint maximal invariant subspaces .......... 373

Mitsuru Nakai, Radon-Nikodým densities and Jacobians .............. 375

Mitsuru Nakai, Royden algebras and quasi-isometries of Riemannian manifolds. . .

Russell Daniel Rupp, Jr., A new type of variational theory sufficiency

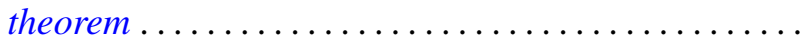

Helga Schirmer, Fixed point and coincidence sets of biconnected multifunctions on trees..........................

Murray Silver, On extremal figures admissible relative to rectangular

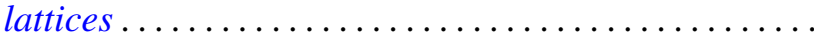

James DeWitt Stein, The open mapping theorem for spaces with unique segments ...

Arne Stray, Approximation and interpolation

Donald Curtis Taylor, A general Phillips theorem for $C^{*}$-algebras and some applications

Florian Vasilescu, On the operator $M(Y)=T Y S^{-1}$ in locally convex algebras...

Philip William Walker, Asymptotics for a class of weighted eigenvalue problems...

Kenneth S. Williams, Exponential sums over $\mathrm{GF}\left(2^{n}\right)$. 